\title{
PREFACE
}

\section{The False Promise of Digital Activism}

For almost two decades, the internet has been hailed as a revolutionary leveling force that is reshaping activism, particularly following the rise of social media. In 2017 alone, one could find examples in several powerful hashtag protests. There was \#MeToo, launched in the wake of a Hollywood sexual harassment scandal that would eventually topple celebrities and politicians alike well into 2018. There was \#WomensMarch, which ignited some of the largest simultaneous mass protests the world had ever seen. Activism seemed cheap, accessible, fast, and open to all. With the right hashtag, it appeared that all it takes to start a movement is the right status update, and suddenly, a nobody from nowhere can change the world.

However, after having the playing field largely to itself for years, this celebratory narrative now finds itself competing with an increasingly sinister view of the internet. A murmur of dissent on digital platforms and politics grew into a roar following the election of President Trump. Platforms like Facebook and Twitter, once the darlings of digital democracy, were suddenly on the defensive for their role in promoting fake news. Concerns about privacy multiplied as revelations grew that some companies may be harvesting 
social media data to manipulate voters. Russia's role was being heavily scrutinized. Harassment, particularly of women, seemed unstoppable. Terrorists were turning to social media to spread violent propaganda. Trolls, bots, and hackers were subjects of congressional hearings. And above it all was a growing fear that the internet was a thing beyond anyone's control, that it had opened the door to an activism far darker and more destructive than once thought possible.

The earlier Edward Snowden revelations of the government's digital spying had put a crack in the utopian digital vision of the internet. But it had taken several years, and the shock election of Trump, for much of the Western world to wake up to the ways the internet could be used to stifle democratic movements. By early 2018, the battle for the soul of digital activism was in full swing. Young students took to social media to demand more protection from gun violence. Swarms of Twitter bots flew into action to shout them down online.

Good. Bad. Utopian. Dystopian. The impact of digital technologies on political activism has exploded into a global conversation, a furious debate over the role that platforms like Facebook, Twitter, and YouTube now play in giving voice to those previously unheard. While this may be new territory for many, it has been central to the questions that my research has explored over the past decade: Who is able and motivated to make use of these new digital tools? And how does this shape their activism?

The impetus to explore the intersection of digital media and activism is both personal and professional for me. It derives from my experiences on the ground with communication technologies and social movements, experiences that inspired me to want to push beyond breezy headlines about hashtag activism. In 1988, as an undergraduate at Duke University, I spent time in Central America, where the United States was waging a covert war against popular movements. In an effort to stop the American military intervention, local activists encouraged me and other North Americans to get the word out about what we had witnessed. And thousands of internationalists like me did just that. Back in this pre-internet age, I wrote articles for student and community publications. Others were doing everything from writing letters to the editor and in newsletters to speaking in church basements and universities.

Later, I embraced video as a way for local people to be able to tell their stories directly, rather than through intermediaries like me. I was hooked. 
The availability of VHS video seemed to be a revolutionary way for stories about the disenfranchised to reach a wider audience. While still a student at Duke University, I disseminated one copy of a video that the United Farmworkers had made to promote their California grape boycott in protest of the toxic chemicals that agribusinesses were using. I showed the video of farmworkers' own voices (with the help of a celebrity voiceover) to different campus groups, classes, and administrators, eventually convincing the university to support their boycott.

After college, I stumbled into a career as a documentary filmmaker. I started modestly, wanting to get the stories out about injustices in the American Black Belt South. A friend and I made a documentary about a group of Black farmers and residents whose drinking water had been contaminated from a nearby factory. If I had known how much work went into making such a video, I'm not sure I would have ever started. But I fell in love with the power of people being able to tell their own story. Yet it was still indirect and time-delayed.

I continued to do a variety of communication work for nonprofit groups, from producing videos and designing newsletters to making buttons and T-shirts. But video was my passion, even though time and gaining access to equipment remained big hurdles. I would often borrow cameras from schools and universities or take advantage of public access stations. These used to be some of the only ways that everyday people could use professional videoediting equipment and get their videos broadcast.

By the mid-to-late 1990s, digital video cameras and editing radically transformed shooting and editing film. I went into the Philippine jungle with a filmmaking partner to interview rebel guerillas for one of my documentaries. We were spared having to haul a large, analog video camera, let alone a $16 \mathrm{~mm}$ camera with large reels of film, as we hiked at night to avoid government detection. In our case, two people were enough to shoot countless hours of footage and edit it on a Mac. By the time this film premiered in 1999, it felt like we were part of another media revolution. Even so, distribution of video itself had not changed. Social movement groups were launching their own websites, but I still had to distribute videos through touring, film festivals and public television.

The real game changer for technology that activists would eventually embrace in public displays of digital activism came in 2006. YouTube exploded into the public's eye with its sale to Google, Facebook became 
available to the general public for the first time, and Twitter was launched. Time magazine named online content creators the "Person of the Year." Streaming and communicating were more direct than ever before and, with mobile devices, were taking the tech scene by storm.

Wanting to investigate the intersection of these digital technologies with inequalities and social movements, I began my graduate studies at Harvard University that same year. I was intrigued by their potential, but skeptical that such a phenomenon would truly level the field, especially given how much work I knew it took to digitally produce and distribute compelling political stories. And yet, my own career made it clear that each new technological evolutionary step had profound consequences for who told stories and how. It was critical for me to fully grasp who was benefiting and who was being left behind as the digital sands shifted.

When I began my sociology doctoral studies at the University of California at Berkeley in 2007, I first tackled fundamental questions of the digital divide, looking at who was able to take advantage of creating online content-and who was not. From there, I took my digital questions more directly to the social movement realm in 2011. At that point, much of the digital activism analysis seemed to revolve around headline-grabbing protests such those in the Middle East and on Wall Street. But these studies seemed inevitably to focus solely on left-leaning groups and flashpoints. Having been part of activism campaigns that spanned years and seen the intensity of labor involved and the drudgery of the tasks it took to build a movement step by step, I wanted to find out how everyday people and movements were using digital technology for their activism.

But how? To compare different types of social movement groups and how they used the internet, I had to find one issue that included a variety of people. I didn't want to start at the tip of the digital activism iceberg - the high-profile movements that had already made it to the top. I wasn't interested in cherry-picking a movement that we already knew used the internet and then make claims about how the internet has changed social movements. I was interested in the opposite-how different types of social movement groups might change how they used the internet.

So it made sense to go back to North Carolina, which not only had the far-right, moderate conservatives, and liberals, but also far-left groups. I already had a good lay of the political land, so to speak, and I was familiar with one issue that captured all these differences: public employees' struggle 
for union rights. I was familiar with this issue as I had been a state worker myself, having worked for several years as a video producer for the North Carolina Agency for Public Telecommunications. I had even made a video for North Carolina Public Television about the challenges faced by lowpaid public employees.

I had remained aware from a distance of the various political and economic battles facing North Carolina public workers. I knew that the growth of the Tea Party and other conservative groups had taken on this issue of public-employee collective bargaining with a passionate opposition. So I began diving back into this landscape to map out the political battleground and players.

All in all, I found 34 groups who were active around this issue-some poor, others with money; some left-leaning, others right-leaning; some horizontal, others hierarchical. I also found new and young groups, as well as those that had been around awhile with older members. The groups ranged from labor unions and worker centers to civil rights and student groups, all supporting the labor rights issue. Opposing unionization were Tea Party and other far-right Patriot groups, as well as conservative think tanks and professional political organizations. The research was built on a foundation of data I gathered from their use of Twitter, Facebook, and websites. But it was shaped equally by the many hours I spent visiting and observing individuals and organizations across this universe of 34 groups, attending town halls and meetups and organizing drives.

I found three main factors that shaped digital activism, which I used to organize this book. While I include all 34 groups in my digital activism index, each chapter zooms into a few organizations that exemplify a specific factor. The introductory chapter unpacks both the conventional wisdom and intellectual puzzles around digital activism differences. In this chapter, I also explain how North Carolina, as a battleground state with both a hightech industry and top universities, as well as some of the poorest areas in the country, is an ideal place to capture the gamut of experiences that social movement groups might encounter in using digital technologies.

Chapter 1 tackles the foundational question about whether or not digital activism levels the playing field between those from different socioeconomic classes. I measured not only how much different groups were posting and interacting online, but also how the actual content varied, depending on the class makeup of the group. I uncovered mechanisms of digital differences 
that go beyond whether or not groups have access to digital gadgets or if they have the skills to go online. By spending time with predominantly African American public employees in the far reaches of rural North Carolina, I learned how harnessing the power of the internet may not be so simple in a context of repression and racism.

Chapter 2 confronts the common wisdom that digital activism has flourished across horizontal movements, as opposed to digitally stifling hierarchical organizations. I analyze measures of hierarchy and bureaucracy, such as decision-making levels and numbers of staff, in comparison to a group's level of digital engagement. And with an in-depth look at everyday digital organizing practices, I compare both a structured teachers' union and a horizontal student group. Both groups embraced the internet, but it turned out that digital engagement thrives on organizational roots more than even I had expected.

Chapters 3 and 4 delve more deeply into the political motivation of social movement groups to use the internet. In Chapter 3, I compare right and left activists but focus on grassroots conservative groups. This digital account of Tea Party and far-right Prepper activists dispels the myth of conservatives as dupes in a Koch brothers' conspiracy. They were digital evangelizers in their own right. By peeling back the layers of hype, I show how average conservative activists used the internet to go around a mainstream media they believed didn't represent them anymore.

But political ideology is not simply a right-versus-left phenomenon, so Chapter 4 takes a look at how groups' political strategies-whether they lobby for reform or protest for radical social change—can impact their digital use. To explain this facet of the digital activist gap, I compare two different labor unions: one is reformist and focuses on influencing powerful decision makers, and the other is radical and focuses on organizing the powerless. In the process, both of these unions found themselves on opposite sides of an insurgent social justice movement, Moral Monday, which emerged in North Carolina in 2013 and sparked waves of protests across the state. This protest movement led to one of the most surprising findings of digital activism in the book, countering the prototypical view of an online warrior as a radical leftist.

Finally, the book's conclusion raises the issue of what is at stake with this digital activism gap, in light of the moral panic around Trump's tweets, Russian bots, or cries of fake news. This pendulum swing of fear around the internet and politics fails to consider the people and organizations on the 
ground who are the ones generating, regurgitating, remixing, and replying to online information, whether on the right or on the left.

It is my hope that people from both sides of the ideological divide will find the following stories, data, and theories of interest-whether they are activists, policy makers, journalists, tech workers, or the general public. The book is for those who want a deep digital dive into what it takes to do everything from organize a protest to click on a political meme. As an academic, I am in direct conversation with other sociologists and political scientists, as well as colleagues in communication, media, and journalism. But because I delve into current debates around inequality, organizations, movements, unions, and, yes, politics, this book is for anyone concerned about these issues.

Throughout my work, the digital tools being used in the political realm have never ceased to evolve and multiply. New tools like messaging apps and Snapchat have grown in power. The Facebook of 2019 is not the Facebook of 2009. Not only are the features infinitely more rich and nuanced, but the platform reaches more than 2 billion people on the planet. The only thing we can predict today is that this iteration will never end, and new gadgets and faster connections will offer new twists and turns.

But each of these generations of digital tools eventually collides with the reality of people's lives and circumstances. Whether it's a VHS cassette tape, or a Russian bot, there are some basic truths about the potential of new technologies to augment political activism. This book is an attempt to shed light on the reality of what happens where the activist meets the digital. 

The Revolution That Wasn't 
